Tema: Aciaria Elétrica

\title{
OBTENÇÃO DE ESCÓRIA ESPUMANTE EM FORNO ELÉTRICO A ARCO: DETERMINAÇÃO DAS COMPOSIÇÕES PARA O SISTEMA $\mathrm{CaO}-\mathrm{SiO}_{2}$-MgO-FeO*
}

\section{Resumo}

Mateus Alves Segundo Paulino Jeferson Leandro Klug ${ }^{2}$ Wagner Viana Bielefeldt ${ }^{3}$ Antônio Cezar Faria Vilela ${ }^{4}$ Nestor Cezar Heck ${ }^{5}$

No estudo de escórias de fornos elétricos a arco (FEA), o sistema $\mathrm{CaO}-\mathrm{SiO}_{2}-\mathrm{MgO}$ FeO se destaca em importância quando os temas são a proteção aos refratários básicos e a produção de 'escória espumante'. A importância da obtenção da escória espumante no FEA reside no fato reconhecido de que ela traz diversas vantagens para a produção de aço, tais como: economia considerável de energia elétrica, proteção de painéis, redução de ruído, redução no consumo de eletrodos, etc. Levando-se em conta que diversos fatores ligados à composição química são de grande importância na produção e estabilidade de bolhas de $\mathrm{CO}$, neste trabalho diferentes diagramas de fase são produzidos como ferramentas para a previsão da composição das escórias mais favoráveis para a formação da espuma. São consideradas na investigação algumas características relevantes encontradas no FEA tais como: basicidade da escória, temperatura de $1.600^{\circ} \mathrm{C}$ e teores de $\mathrm{FeO}$ e MgO variáveis (que refletem os diversos níveis de oxidação do banho).

Palavras-chave: FEA; Escória espumante; Termodinâmica computacional.

\section{Abstract}

\section{STUDY OF FOAMING SLAGS IN ELECTRIC ARC FURNACE}

In the study of electric arc furnaces (EAF) slags, the system $\mathrm{CaO}-\mathrm{SiO}_{2}-\mathrm{MgO}-\mathrm{FeO}$ stands out in importance when the topics are basic refractory protection and production of 'foaming slag'. The importance of obtaining foaming slag in EAF is recognized by the fact that it brings many advantages for the production of steel, such as considerable savings in electricity, panels protection, noise reduction, reduced electrodes consumption, etc. Taking into account that several factors related to the chemical composition are of great importance in the production and stability of CO bubbles, in this study different phase diagrams are produced as a tool to predict the more favorable slag composition for foam formation. Some relevant features found in EAF such as slag basicity, temperature of $1,600^{\circ} \mathrm{C}$ and $\mathrm{FeO}$ and $\mathrm{MgO}$ variables contents (which reflect the different bath oxidation levels) were considered in this investigation.

Keywords: EAF; Foaming slags; Computational thermodynamics.

1 Engenheiro Metalúrgico, Mestrando, Departamento de Engenharia Metalúrgica e de Materiais, PPGECM, UFC, Fortaleza, Ceará, Brasil.

2 Engenheiro Metalúrgico, Professor Doutor, Departamento de Engenharia Metalúrgica e de Materiais, PPGECM, UFC, Fortaleza, Ceará, Brasil.

3 Engenheiro Metalúrgico, Professor Doutor, Departamento de Metalurgia, LASID, PPGE3M, UFRGS, Porto Alegre, Rio Grande do Sul, Brasil.

4 Engenheiro Metalúrgico, Professor Doutor, Departamento de Metalurgia, LASID, PPGE3M, UFRGS, Porto Alegre, Rio Grande do Sul, Brasil.

5 Engenheiro Metalúrgico, Professor Doutor, Departamento de Metalurgia, NTCm, PPGE3M, UFRGS, Porto Alegre, Rio Grande do Sul, Brasil.

\footnotetext{
* Contribuição técnica ao $45^{\circ}$ Seminário de Aciaria - Internacional, 25 a 28 de maio de 2014,
} 


\section{INTRODUÇÃO}

A siderurgia proveu a Humanidade com o material ferro obtendo-o, a partir dos seus minérios, com processos metalúrgicos de redução (metalurgia primária). Na medida em que a civilização evoluiu, objetos de aço derivados da obsolescência de estruturas, veículos, objetos, etc. (sucata) começaram a ficar disponível em tal abundância que isso deu origem a um novo método de produção de aço, a partir da sucata (metalurgia secundária).

O aço desta nova rota é obtido basicamente via aciaria elétrica. A aciaria elétrica, metalurgicamente, é composta de duas etapas: a oxidante e a redutora; genericamente, na primeira (refino primário) ocorre a fusão da sucata e a desfosforação do aço enquanto na segunda (refino secundário) é feita a dessulfuração e ajustes na composição e na temperatura. Os reatores principais utilizados na aciaria elétrica são: o forno elétrico a arco, FEA, e o forno panela, FP, na primeira e na segunda etapa, respectivamente.

As escórias, em função das etapas, são divididas em dois tipos e suas composições refletem isso, Tabela 1.

Tabela 1. Composição representativa das escórias das etapas oxidante e redutora da aciaria elétrica (teores em \% ponderal)

\begin{tabular}{|c|r|r|}
\hline Componente & Oxidante & Redutora \\
\hline $\mathrm{CaO}$ & 22.8 & 55.1 \\
\hline $\mathrm{SiO}_{2}$ & 12.1 & 18.8 \\
\hline Óxidos de $\mathrm{Fe}$ & 29.5 & 0.3 \\
\hline $\mathrm{MgO}$ & 4.8 & 7.3 \\
\hline $\mathrm{Al}_{2} \mathrm{O}_{3}$ & 6.8 & 16.5 \\
\hline $\mathrm{S}$ & 0.2 & 0.4 \\
\hline $\mathrm{P}_{2} \mathrm{O}_{5}$ & 0.3 & 0.1 \\
\hline $\mathrm{MnO}$ & 7.9 & 1.0 \\
\hline Fonte: $h$ ttp://www.slg.jp/e/slag/character.html
\end{tabular}

A grande quantidade de óxidos de ferro na escória oxidante se deve à facilidade de oxidação do ferro - especialmente quando a carga contém peças finas e de elevada superfície - em contato com o ar na faixa de temperaturas existente no interior do FEA e à presença prévia de sucata muito oxidada na carga. Já no FP a condição é redutora, o que provoca a recuperação do ferro contido na escória como óxido, e a consequente modificação na sua composição.

Enquanto a primeira destas condições facilita a desfosforação, a segunda favorece a dessulfuração do aço. Isto deixa claro que há um equilíbrio - que pode ser determinado com a ajuda da termodinâmica química - entre a escória e o banho: uma escória contendo óxidos de ferro implica num banho oxidado e vice-versa.

As finalidades da escória são bem conhecidas pelos aciaristas; dentre elas podem ser citadas:

- Isolar o banho, reduzindo as perdas térmicas;

- Proteger o banho da ação dos gases da atmosfera;

- Ajudar na absorção de fósforo e de enxofre;

- Auxiliar no controle dos tipos de inclusões;

* Contribuição técnica ao $45^{\circ}$ Seminário de Aciaria - Internacional, 25 a 28 de maio de 2014, 


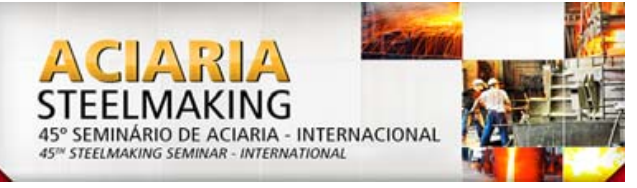

- Controlar os níveis de oxigênio e a composição química do aço;

- Proteger o forno da radiação direta (flare) dos arcos.

A composição química dos refratários dos fornos (na grande maioria dos processos modernos de aciaria) é do tipo 'básica' - o que significa que os óxidos 'ácidos' $\left(\mathrm{SiO}_{2}\right.$, $\mathrm{Al}_{2} \mathrm{O}_{3}$, etc.) bem como o FeO presentes na escória vão atacá-los e corroê-los por ação química. A escória, portanto, deve ser 'desequilibrada' para o lado 'básico' (quociente entre os óxidos 'básicos' e os 'ácidos' da escória deve ser maior do que a unidade), a fim de se evitar a erosão dos refratários.

Por outro lado, um fator de reconhecida importância na aciaria é a possibilidade de se produzir uma 'escória espumante' (contendo bolhas de CO que aumentam seu volume até encobrir os arcos dos eletrodos), que, no FEA, diminui o consumo dos eletrodos e protege os painéis refrigerados. Isso produz uma melhoria na eficiência térmica, com uma consequente diminuição no tempo de fusão - pois esta prática permite a manutenção de uma potência elevada, mesmo ao final da fusão da sucata -, com impactos econômicos positivos na produção do aço.

Para a promoção de ações de formação de espuma (desde que haja condições físico-químicas adequadas, genericamente: alta viscosidade, baixa densidade e baixa tensão superficial [1]) e para a manutenção de uma escória 'básica' deve-se adicionar $\mathrm{CaO}$ (cal calcítica - de elevada concentração de $\mathrm{CaO}$ ) e $\mathrm{MgO}$ (cal dolomítica, contendo $\mathrm{CaO}$ e $\mathrm{MgO}$ ) à escória, para além da saturação. Diz-se, de uma escória nesta condição, que ela se encontra 'duplamente saturada'.

Portanto, quatro variáveis podem ser destacadas: MgO, FeO, temperatura e basicidade. O objetivo do presente trabalho é analisar, com base numa ferramenta termodinâmica computacional, as relações fundamentais entre a basicidade e os conteúdos de $\mathrm{MgO}$ e $\mathrm{FeO}$ (a uma temperatura fixa de $1600^{\circ} \mathrm{C}$ ) para entendimento das questões anteriormente referidas. Para este estudo será utilizado um sistema composto pelos óxidos $\mathrm{CaO}-\mathrm{SiO}_{2}-\mathrm{MgO}$, adicionado mais tarde com $\mathrm{FeO}$.

\section{METODOLOGIA}

O aplicativo germânico-canadense 'FactSage' (versão 6.4) [2] foi usado em todas as determinações termodinâmicas do estado de equilíbrio do presente trabalho. Os estados de equilíbrio neste software são determinados pela minimização da energia de Gibbs por meio da técnica dos coeficientes de Lagrange.

O banco de dados termodinâmicos 'FToxid' do grupo canadense FACT foi o principal banco utilizado; seus componentes principais são os óxidos $\mathrm{Al}_{2} \mathrm{O}_{3}, \mathrm{CaO}, \mathrm{FeO}$, $\mathrm{Fe}_{2} \mathrm{O}_{3}, \mathrm{MgO}$ e $\mathrm{SiO}_{2}$. Este banco é composto por duas bases de dados, descritas a seguir: a base FToxid-soluções (FToxid53soln.sda, 2013), que contém dados de soluções sólidas e liquida de óxidos, e a base FToxid-compostos (FToxid53base.cdb, 2013), que contém dados de compostos óxidos estequiométricos sólidos e líquidos. Ambas foram avaliadas e, sempre que possível, otimizadas pelo grupo FACT e, segundo os fornecedores, elas são termodinamicamente compatíveis entre si.

A fase mais importante da base de dados FToxid-soluções é a solução líquida "escória líquida" FToxid-SLAGA. Os óxidos mais importantes, constituintes desta solução, são: Al, As, B, Ca, Co, Cr(II), Cr(III), Cu(I), Fe(II), Fe(III), Ge, K, Mg, Mn(II), $\mathrm{Mn}(\mathrm{III}), \mathrm{Na}, \mathrm{Ni}, \mathrm{Pb}, \mathrm{Si}, \mathrm{Sn}, \mathrm{Ti}(\mathrm{III}), \mathrm{Ti}(\mathrm{IV}), \mathrm{Zn}, \mathrm{Zr}+$ (S em solução diluída (<10\%)).

* Contribuição técnica ao 45 Seminário de Aciaria - Internacional, 25 a 28 de maio de 2014, 


\section{RESULTADOS}

\subsection{Sistema $\mathrm{CaO}-\mathrm{SiO}_{2}-\mathrm{MgO}$}

Conforme referido, refratários à base de magnésia são severamente atacados por escórias não-saturadas em MgO. O limite de saturação em MgO está relacionado com a concentração de outros componentes (óxidos) da escória e com a temperatura do processo. Os efeitos da MgO foram estudado inicialmente para um sistema mais simples, composto pelos óxidos $\mathrm{CaO}_{-} \mathrm{SiO}_{2}-\mathrm{MgO}$, à temperatura (constante) de $1600^{\circ} \mathrm{C}$; os resultados podem ser vistos no diagrama da Figura 1.

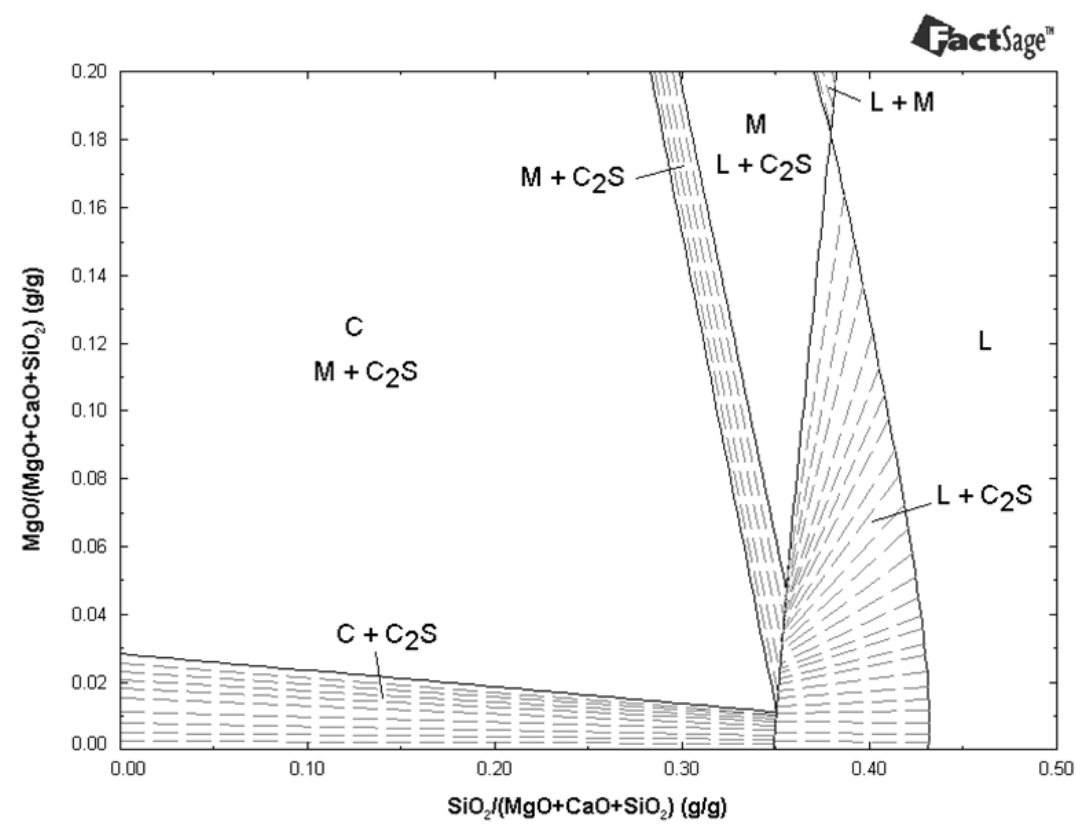

Figura 1. Diagrama de fases em equilíbrio, sistema $\mathrm{CaO}-\mathrm{SiO}_{2}-\mathrm{MgO}$ (canto rico em $\mathrm{CaO}$ ), à temperatura de $1600^{\circ} \mathrm{C}$, em função das frações ponderais de $\mathrm{SiO}_{2}$ e $\mathrm{MgO}$; à direita da região central da figura apresenta-se o campo com 'dupla saturação' $\left(M+L+C_{2} S\right)$; fases: $C=C a O, M=M g O, C_{2} S=$ $\mathrm{Ca}_{2} \mathrm{SiO}_{4}$ e L= escória (fase líquida)

A Figura 1 mostra claramente que as fases condensadas descritas na base de dados do grupo FACT são do tipo solução (ao contrário da situação comumente encontrada na literatura). Assim, a fase 'CaO' (C) forma uma solução sólida, dissolvendo até $-3 \%$ de $\mathrm{MgO}(\mathrm{M})$, e a fase $\mathrm{Ca}_{2} \mathrm{SiO}_{4}\left(\mathrm{C}_{2} \mathrm{~S}\right)$ dissolve este componente até aproximadamente $5 \%$ em massa, à temperatura de $1600^{\circ} \mathrm{C}$.

O teor mínimo de $\mathrm{MgO}$ no sistema pseudoternário $\mathrm{CaO}-\mathrm{SiO}_{2}-\mathrm{MgO}$ necessário para a dupla saturação (em $\mathrm{MgO}$ e $\mathrm{Ca}_{2} \mathrm{SiO}_{4}$ ) da escória com foi recalculado e pode ser visto na Figura 2 em função da basicidade binária $\left(\mathrm{B}_{2}=\mathrm{CaO} / \mathrm{SiO}_{2}\right)$; assim, fica fácil constatar que, quanto mais baixa for a basicidade do sistema, tanto maior será a necessidade de $\mathrm{MgO}$ para o estabelecimento de estados de equilíbrio termodinâmico com dupla saturação.

* Contribuição técnica ao $45^{\circ}$ Seminário de Aciaria - Internacional, 25 a 28 de maio de 2014, 

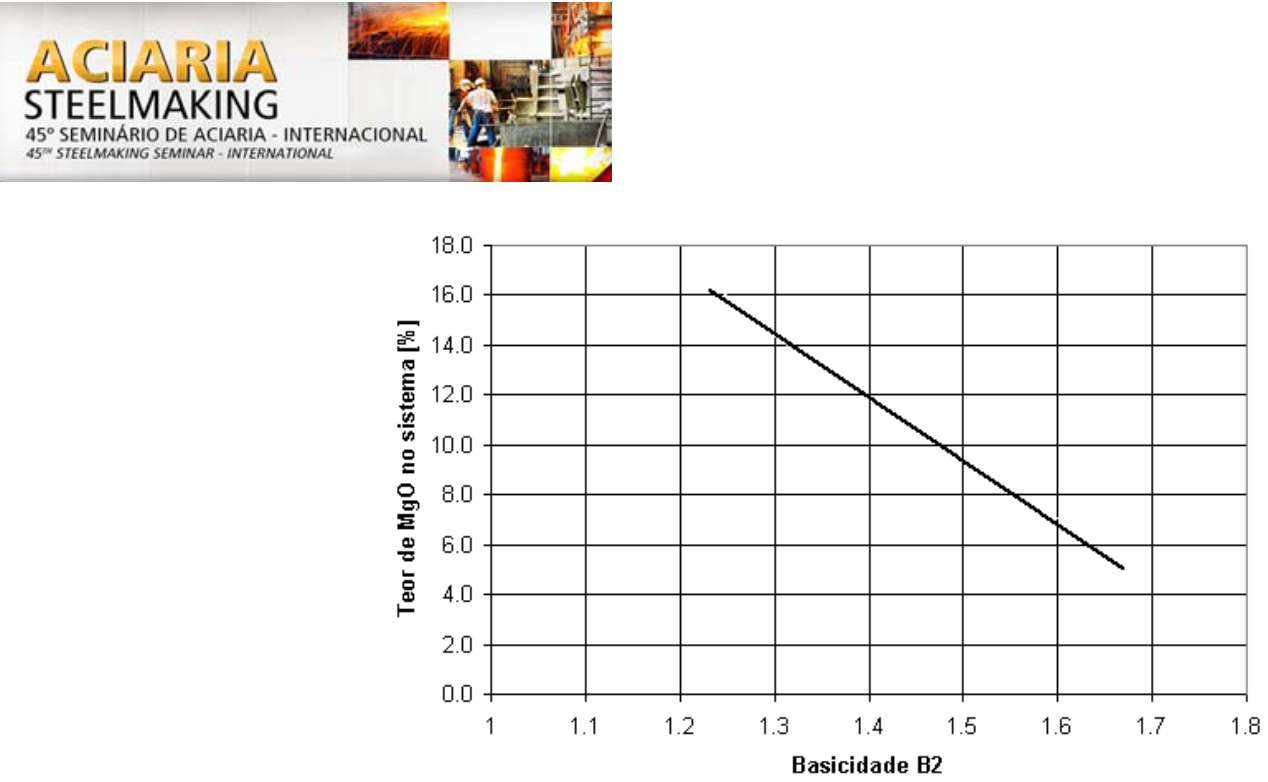

Figura 2. Teor mínimo de MgO (ponderal) no sistema ternário necessário para a obtenção de uma escória com dupla saturação (em $\left.\mathrm{M} \mathrm{e} \mathrm{C}_{2} \mathrm{~S}\right)$, em função da basicidade binária $\left(\mathrm{B}_{2}=\mathrm{CaO} / \mathrm{SiO}_{2}\right)$

\subsection{Sistema CaO-SiO $-\mathrm{MgO}-\mathrm{FeO}$}

Para o entendimento básico do comportamento das escórias no FEA, pode-se usar o sistema pseudoternário $\mathrm{CaO}-\mathrm{SiO}_{2}-\mathrm{MgO}$; contudo, por causa da grande fração de óxidos de ferro na fusão, ele se mostra demasiadamente simples para suportar estudos mais detalhados; torna-se necessário tomar também o Fe em consideração. Supondo-se que a escória que entra em contato físico com o aço líquido é aquela mais interessante de ser analisada, então se justifica a adoção do sistema CaO$\mathrm{SiO}_{2}-\mathrm{MgO}-\mathrm{FeO}$ como objeto de estudo, ao invés do $\mathrm{Fe}_{2} \mathrm{O}_{3}-$ uma vez que o óxido de ferro de valência mais elevada $\left(\mathrm{Fe}^{3+}\right)$, provavelmente presente na região da escória em contato com o ar, será instável nesta condição mais redutora.

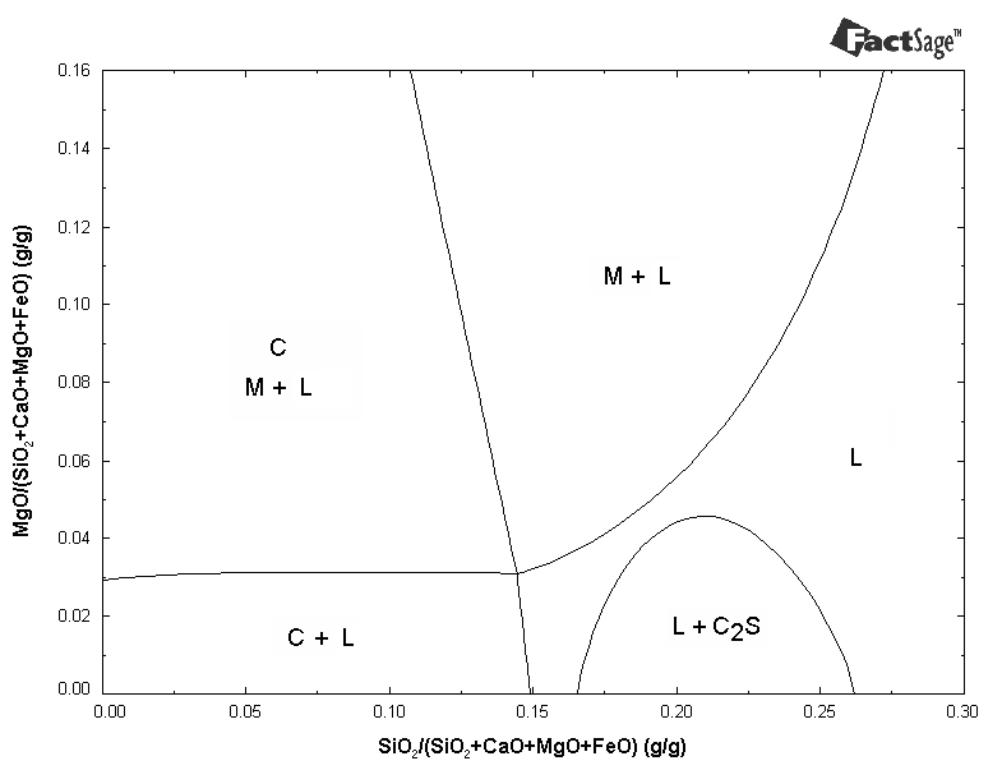

Figura 3. Diagrama de fases em equilíbrio, sistema $\mathrm{CaO}-\mathrm{SiO}_{2}-\mathrm{MgO}-\mathrm{FeO}$ (canto rico em $\mathrm{CaO}$ ), à temperatura de $1600^{\circ} \mathrm{C}$, em função das frações ponderais de $\mathrm{SiO}_{2}$ e $\mathrm{MgO}$; teor fixo de $\mathrm{FeO}=33 \%$ ponderal.

Assim, levando-se em consideração esta condição, o diagrama da Figura 1 foi refeito para um teor fixo de FeO de 33 \% em peso, Figura 3.

Pode-se observar nesta figura que a fase $L$ (escória) está presente em todos os campos - evidenciando a natureza fundente do óxido de ferro. A fase $\mathrm{C}_{2} \mathrm{~S}$, ao

* Contribuição técnica ao $45^{\circ}$ Seminário de Aciaria - Internacional, 25 a 28 de maio de 2014, 
contrário, antes presente em vários campos de fases, tem a sua área de existência restringida, reduzindo-se a uma pequena região próxima ao teor de $22 \%$ de $\mathrm{SiO}_{2}$ em peso (essa fração ponderal é enganosa, pois, a proporção entre $\mathrm{CaO}$ e $\mathrm{SiO}_{2}-$ ou basicidade binária - permanece, evidentemente, a mesma). Por conta deste recuo, o campo de dupla saturação $\mathrm{M}+\mathrm{C}_{2} \mathrm{~S}$ desaparece do diagrama.

Pretorius [3,4], estudando as condições mais adequadas para a formação de escória espumante, o faz usando diagramas que poderiam ser vistos como cortes transversais na Figura 3, cada um com uma basicidade $\left(\mathrm{B}_{3}=\mathrm{CaO} /\left(\mathrm{SiO}_{2}+\mathrm{Al}_{2} \mathrm{O}_{3}\right)\right)$ fixa. Tais diagramas foram denominados pelo autor como 'diagramas isotérmicos de solubilidade' (Isothermal Solubility Diagrams, ISD), e foram usados por diversos autores em análises de escórias nesta condição oxidante [5-7].

Pretorius salienta que, na região totalmente líquida da escória, são 'pobres' as condições para a formação de uma escória espumante. Segundo ele, melhores condições são encontradas na borda externa do campo monofásico 'L' (para além da fronteira liquidus), pois a presença de fases sólidas precipitadas dá condições físico-químicas mais favoráveis para o desenvolvimento desta classe de fenômenos. Fica ressaltado no seu trabalho que uma superprecipitação com partículas secundárias produz uma escória excessivamente 'rígida' (crusty) - não indicada - e que uma escória a meio termo entre este ponto e a fronteira liquidus (creamy), teria a condição ideal (fluffy), medida por um 'índice de formação de espuma' (foaming index, $\Sigma$ ). Estes pontos ficam estabelecidos por uma linha tracejada que bordeia, a certa distância, o campo monofásico 'L' (líquido), no trabalho original, Figura 4.

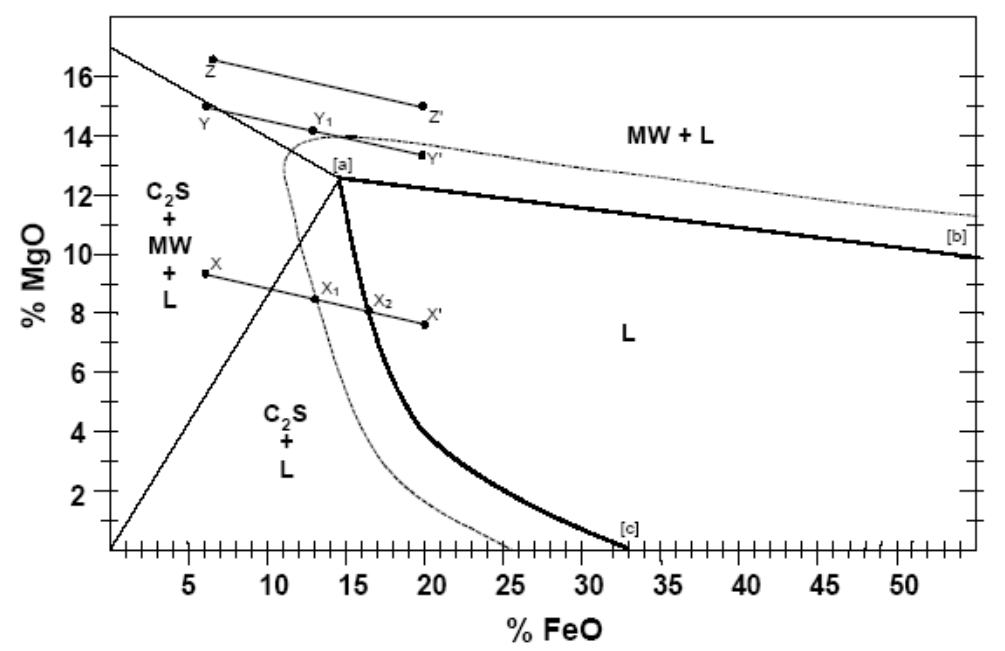

Figura 4. Diagrama de fases em equilíbrio à basicidade constante $\left(B_{3}=1,5\right)$, tipo ISD (canto rico em $\mathrm{CaO}$ ), à temperatura de $1600^{\circ} \mathrm{C}$, em função das frações ponderais de $\mathrm{MgO}$ e FeO; a linha tracejada denota a melhor composição para a formação de escória espumante; MW= magnésio-wustita [3].

Quatro diagramas com basicidade $B_{2}$ constante foram traçados neste trabalho para delimitar a fronteira do campo monofásico 'líquido' (escória líquida).

O primeiro, Figura 5, feito para uma basicidade binária igual a 1,5, é similar ao diagrama mostrado por Pretorius (sistema mais complexo), e possui as mesmas fases, Figura 4. Algumas discrepâncias podem possivelmente ser atribuídas ao fato que, neste trabalho, somente modelos do tipo 'solução' foram utilizados para todas as fases envolvidas - ao invés de se fazer uso, também, de fases do tipo 'compostos estequiométricos'.

* Contribuição técnica ao $45^{\circ}$ Seminário de Aciaria - Internacional, 25 a 28 de maio de 2014, 


\section{STEEIMAKING}

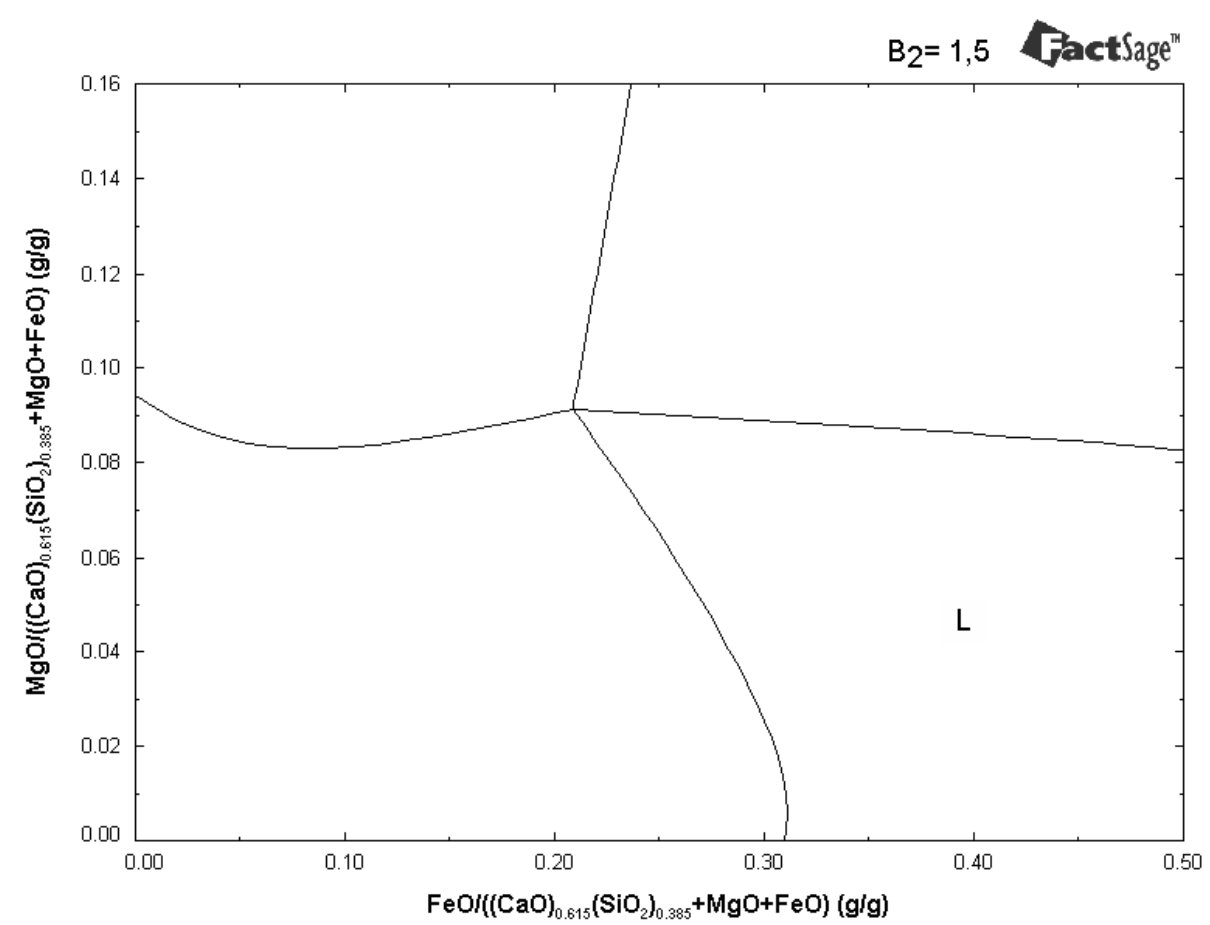

Figura 5. Diagrama de fases em equilíbrio, tipo ISD, basicidade constante $B_{2}=1,5$; $L=$ escória (fase líquida).

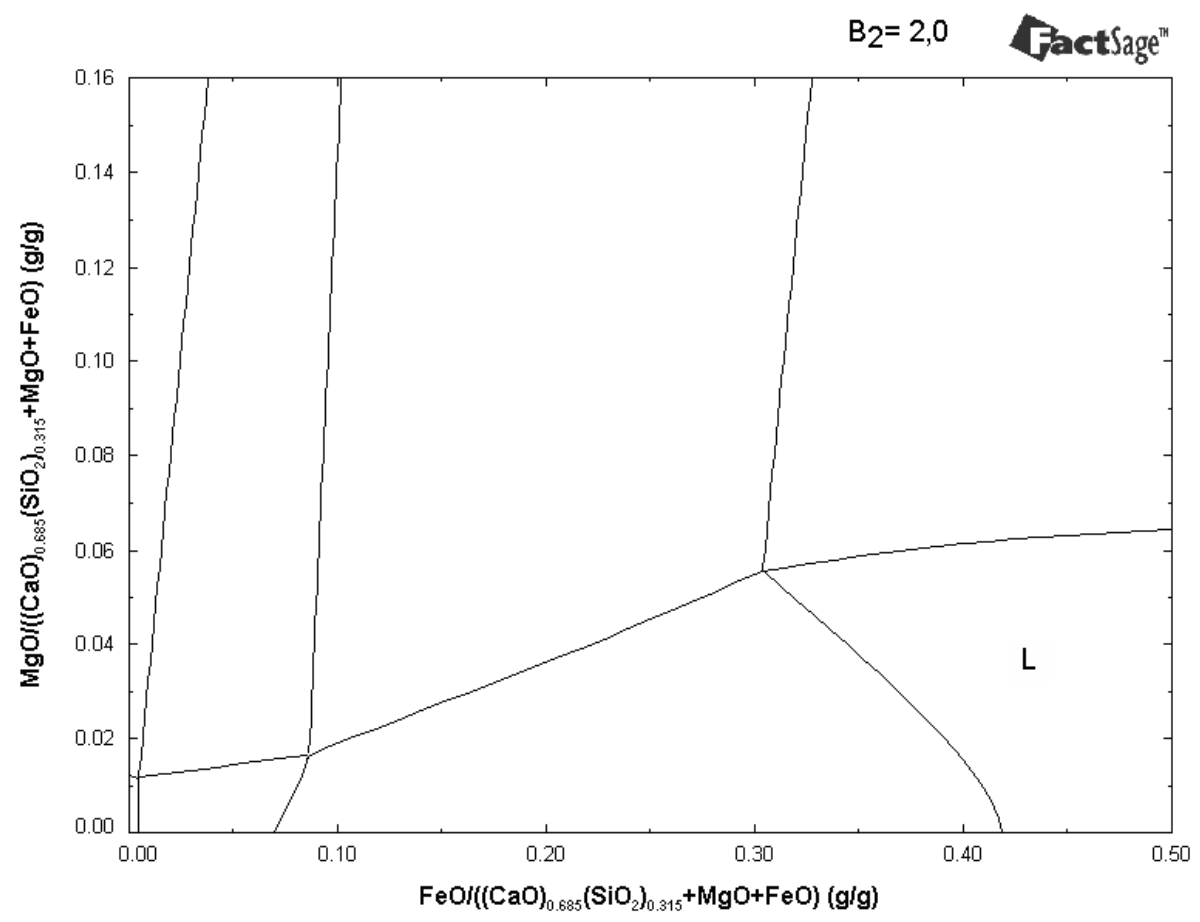

Figura 6. Diagrama de fases em equilíbrio, tipo ISD, basicidade constante $B_{2}=2,0$; $L=$ escória (fase líquida)

* Contribuição técnica ao $45^{\circ}$ Seminário de Aciaria - Internacional, 25 a 28 de maio de 2014, Porto Alegre, RS, Brasil. 

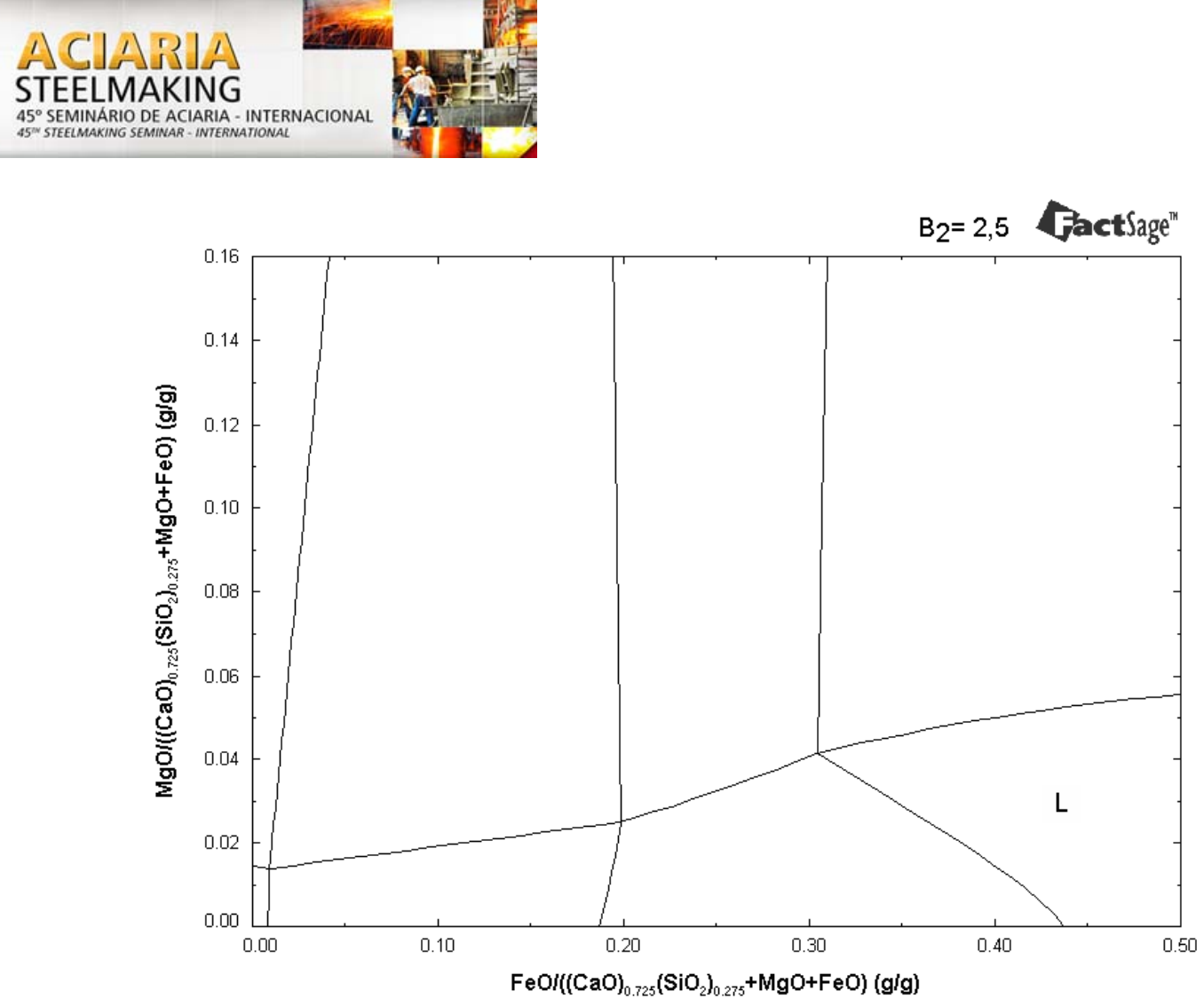

Figura 7. Diagrama de fases em equilíbrio, tipo ISD, basicidade constante $B_{2}=2,5$; $L=$ escória (fase líquida).

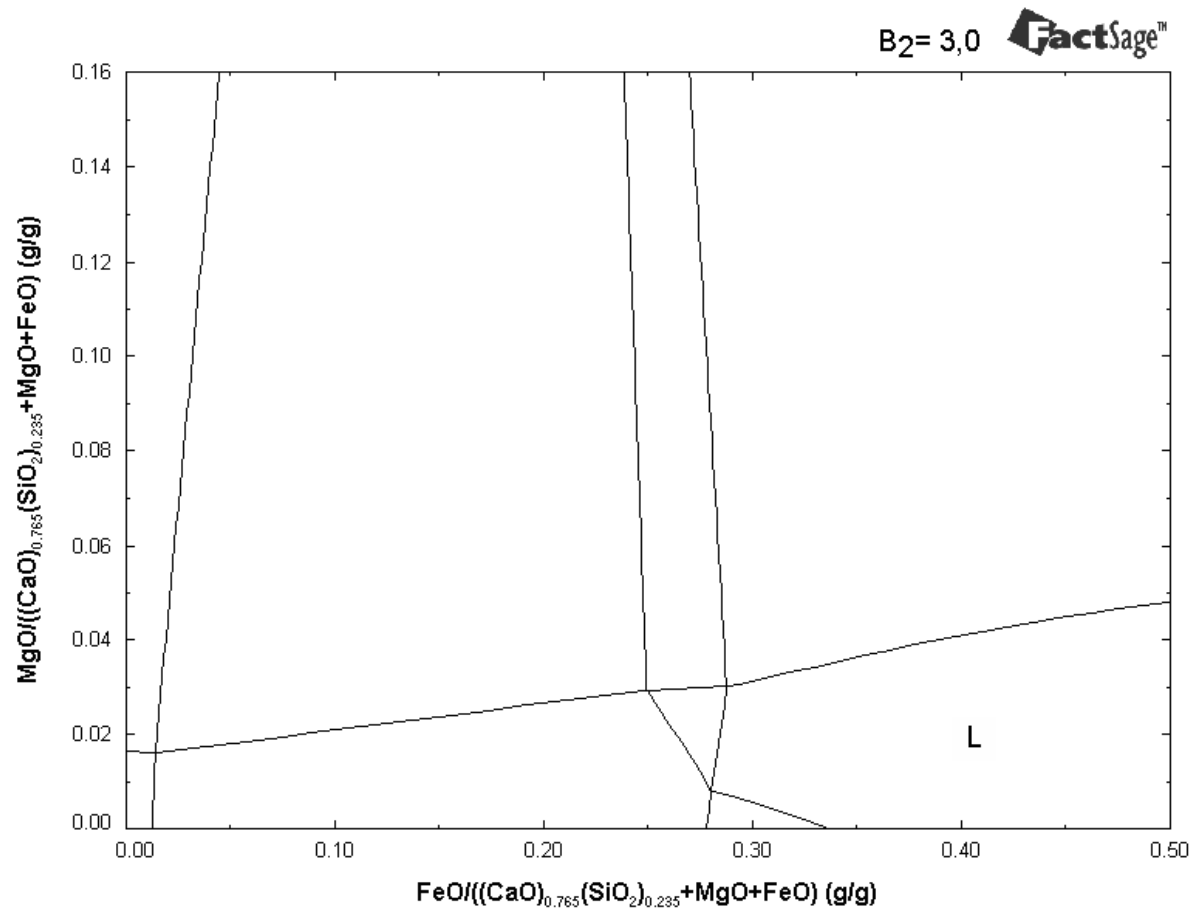

Figura 8. Diagrama de fases em equilíbrio, tipo ISD, basicidade constante $B_{2}=3,0$; $L=$ escória (fase líquida).

Os outros três diagramas do tipo ISD, feitos para as basicidades binárias crescentes: $2,2,5$ e 3 , Figuras 6,7 e 8 , respectivamente, se afastam sensivelmente dos diagramas ISD apresentados por Pretorius para basicidades mais elevadas.

Estes diagramas, contudo, de acordo com o diagrama mostrado para a isopleta $30 \%$ FeO, Figura 3, refletem inicialmente o estreitamento do campo monofásico 'L', à

* Contribuição técnica ao 45 Seminário de Aciaria - Internacional, 25 a 28 de maio de 2014, Porto Alegre, RS, Brasil. 
medida que a basicidade binária aumenta (ou que o teor de $\mathrm{SiO}_{2}$ cai), até que, ao final, a região líquida volta a crescer.

\section{DISCUSSÃO}

Este trabalho mostra que estudo das escórias da aciaria elétrica em relação à escória espumante (para a maior eficiência energética do processo) e à saturação com $\mathrm{MgO}$ (para a proteção dos refratários do forno) pode ser feito a partir de dois sistemas: $\mathrm{CaO}-\mathrm{SiO}_{2}-\mathrm{MgO}$ e $\mathrm{CaO}-\mathrm{SiO}_{2}-\mathrm{MgO}-\mathrm{FeO}$.

A região com dupla saturação da escória (lida no sistema inicial), com MgO e $\mathrm{Ca}_{2} \mathrm{SiO}_{4}$, mostra apenas as condições ideais para a proteção dos refratários básicos de um forno em contato com a escória (este diagrama também pode ser usado para o estudo fundamental das escórias da produção de aços inoxidáveis numa condição redutora). Para o estudo das condições para a formação da escória espumante na produção de aços ao carbono, torna-se necessária a introdução do FeO no sistema. Desta forma ela irá refletir a etapa inicial da aciaria elétrica, onde as condições de oxidação do sistema são elevadas - por causa do contato direto entre a sucata e o ar, e pela presença de material previamente oxidado compondo a própria carga do FEA.

Com o aumento do componente FeO na composição da escória, o sistema se modifica e tende a ser constituído fundamentalmente pela fase escória (líquida) com ou sem a presença de outras fases precipitadas (simultaneamente a fase $\mathrm{C}_{2} \mathrm{~S}$ perde quase toda a sua importância, e com ela a 'dupla saturação').

Assim, quatro variáveis passam a se destacar: os teores dos óxidos $\mathrm{MgO}$ e $\mathrm{FeO}, \mathrm{a}$ basicidade (binária) e a temperatura do sistema; neste estudo inicial, tanto a variável temperatura quanto a basicidade são eliminadas. A primeira, com a manutenção da isoterma de $1600^{\circ} \mathrm{C}$, e, a segunda, com a construção de 'diagramas isotérmicos de solubilidade', ISD - que são, na realidade, diagramas de 'isobasicidades'. Deste modo, os efeitos das duas variáveis restantes ( $\mathrm{MgO}$ e FeO) podem ser analisadas meio dos diagramas ISD.

Vistos isoladamente, os diagramas ISD mostram claramente as condições de formação de escória espumante preconizadas por Pretorius. $O$ diagrama para $\mathrm{B}_{2}=$ 1,5, Figura 5, por exemplo, mostra que um aumento da FeO abaixa o teor de MgO necessário para se atingir a linha onde as condições físico-químicas da escória são consideradas ótimas (condição 'fluffy' - linha pontilhada da Figura 4). Digna de nota, contudo, é a alteração gradativa da inclinação dessa linha superior de fronteira do campo monofásico 'L' para o restante das basicidades: negativa na primeira, positiva no restante das outras (efeito contrário ao verificado no trabalho original de Pretorius). Com isso, um aumento no teor de FeO teria o efeito contrário ao mencionado anteriormente.

Por outro lado, quando os diagramas são analisados conjuntamente, se pode observar que a saturação da escória se dá com quantidades cada vez menores de $\mathrm{MgO}$, em função de basicidades crescentes (ou seja, a fronteira superior do campo da fase 'L' abaixa, na medida em que a basicidade do sistema aumenta).

\section{CONCLUSÕES}

Este trabalho mostra que estudo das escórias da aciaria elétrica em relação à geração de bolhas (escória espumante) e à saturação com MgO (para a proteção dos refratários do forno) pode se iniciar a partir de dois sistemas: $\mathrm{CaO}-\mathrm{SiO}_{2}-\mathrm{MgO}$ e

* Contribuição técnica ao $45^{\circ}$ Seminário de Aciaria - Internacional, 25 a 28 de maio de 2014, 
$\mathrm{CaO}-\mathrm{SiO}_{2}-\mathrm{MgO}-\mathrm{FeO}$. As quatro variáveis existentesno último, quais sejam: teores dos óxidos que compõem a escória, $\mathrm{MgO}$ e $\mathrm{FeO}$; basicidade e temperatura são reduzidas à apenas duas neste estudo (os teores de $\mathrm{MgO}$ e $\mathrm{FeO}$ ) com o uso de 'diagramas ISD'.

Da sua análise se conclui que, para uma condição de isobasicidade, as condições da formação de escória espumante reproduzem as tendências dos resultados de Pretorius apenas quando os valores de basicidade são baixos; por outro lado, para valores de basicidades crescentes, a saturação da escória se dá com quantidades cada vez menores de $\mathrm{MgO}$ - fato que é reconhecido na prática.

$\mathrm{Na}$ interpretação destes resultados há que lembrar que, na parte superior da escória dentro do forno - onde as condições são fortemente oxidantes, há uma tendência para a formação de $\mathrm{Fe}_{2} \mathrm{O}_{3}-0$ que significa que as condições aqui apresentadas são apenas parcialmente representativas da verdadeira situação.

Resumindo, a informação apresentada neste trabalho pode ser de valor tanto para a compreensão das condições nas quais a escória espumante ocorre, durante a produção de aços ao carbono, quanto para o planejamento de ações a serem tomadas pelo aciarista durante a produção de aço.

\section{REFERÊNCIAS}

1 Morales RD, Lule RG, Lopez F, Camacho J, Romero JA. The slag foaming practice in EAF and its influence on the steelmaking shop productivity. ISIJ International. 1995;35:1054-62.

2 Bale CW, Chartrand P, Degterov SA, Eriksson G, Hack K, Ben Mahfoud R, et al. FactSage termochemical software and databases. Calphad. 2002;26:189-228.

3 Pretorius EB. Fundamentals of EAF and ladle slags and ladle refining principles. Baker Refractories. 1998. p.1-25.

4 Pretorius EB, Carlisle RC. Foamy slag fundamentals and their practical application to electric furnace steelmaking, In: Electric Furnace Conference Proceedings; 1998; New Orleans, EUA. American Institute of Mining, Metallurgical and Petroleum Enginers; 1998. p.275-292

5 Kwong K-S, Bennett J, Krabbe R, Petty A, Thomas H. Thermodynamic calculations predicting $\mathrm{MgO}$ saturated EAF slag for use in EAF steel production. Supplemental Proceed: Materials Characterization, Computation and Modeling. TMS. 2009:63-70

6 Houldsworth IG, Richards P, Edwards GAG. Optimization of steelmaking slag. The refractories engineer. Mar. 2009; p.18-21.

7 Ávila TA. Condicionamento de escórias em forno elétrico a arco para otimização das condições de espumação da escória e refino do aço [dissertação de mestrado]. Belo Horizonte: Universidade Federal de Minas Gerais; 2011.

* Contribuição técnica ao $45^{\circ}$ Seminário de Aciaria - Internacional, 25 a 28 de maio de 2014, 